\title{
User Fulfilment Density Based Access to Intrusion Detection System Selection for WSN
}

\author{
C.Nalini, C. Rajabhushanam, Stephen AntoJegan
}

\begin{abstract}
Interruption Detection System (IDS) is a scheme safety device used in remote sensor systems (WSNs) to identify vulnerability abusses against attacks. The determination of IDS relies upon the WSN engineering and application. It is for the overseer to choose which IDS will be the best answer for the sensor arrange. There is never one arrangement that works for everything so overseer needs to analyse the capacities of every id alongside spending plan and learning. This article gives a weight-based way to deal with a client to deal with IDS assurance for WSN. We initially talk about client WSN IDS prerequisites and WSN IDS measurements, at that point for each WSN IDS necessity we coordinate the worry metric(s). Client records their WSN IDS prerequisites in an incomplete requesting from minimum to generally imperative. Client necessities are typically expressed in a positive shape or changed over to the positive frame. The main prerequisite (i.e. minimum imperative) is relegated the most reduced weight (e.g., one) While the remaining preconditions are assigned to expand weights to their comparative importance. Once weighted, each WSN IDS metric is assigned a weight equivalent to the entire weight of the necessities it adds to.WSN IDS measurements are masterminded in sliding request where metric with the most noteworthy weight is at the best. Proper WSN IDS apparatus might be chosen in the wake of coordinating the measurements weight and IDS highlights.
\end{abstract}

\section{INTRODUCTION}

Security problems are not specific by any stretch of imagination, choosing the association scheme about the needs of the client. The objectives, adequate utilizations, and limitations on the framework are chosen by hierarchical strategy with respect to security. It is hierarchical assertion that will choose what to screen, when to alarm and whom to caution, or up to what level of risk a potential interruption presents. Systems administration has offered ascend to the issue of system security. Interruption As an imperative safety element, detection systems (IDS) have increased. An IDS is a gadget or programming software that is organized by displays as well as context drills for breach of vindictive activities or order and accounts to an administrative office.

Since remote sensor arrange (WSN) is another innovation it additionally has a few vulnerabilities. Items like WSN IDS have happened that address a considerable lot of these. As assortment of WSN IDS are proposed in the writing, it ends up hard to pick and execute one of them as it's a complex and

Revised Manuscript Received on July 22, 2019.

C.Nalini , Department of Computer Science \& Engineering, Bharath Institute of Higher Education and Research, Chennai, India

C. Rajabhushanam, Department of Computer Science \& Engineering, Bharath Institute of Higher Education and Research, Chennai, India

Stephen AntoJegan, Department of Computer Science \& Engineering, Bharath Institute of Higher Education and Research, Chennai, India Email:stephen_jegan@yahoo.co.in tedious procedure. This turns out to be more troubling if there is no commercial safety program for the organization. The choice of assurance of WSN IDS ought not be made rapidly, tenderly or without a solid comprehension of improvement, choices or forthcoming effects. In this archive, we give a client weight-based preconditions for managing the choice of IDS for WSN. In this approach first all conceivable client IDS prerequisites and WSN IDS measurements are recorded. At that point, for every id necessity we discover the worry metric(s). Client records their WSN prerequisites in a halfway requesting from slightest vital to most. Necessities are typically expressed in positive frame or changed over to the positive shape. Next, the primary prerequisite (i.e. minimum critical) is appointed the most reduced weight (e.g., one). Different necessities could be reduced to their comparative importance by increasing weights. Once weighted, each I d metric is relegated to a weight that is equivalent to the whole weight of the necessities it adds to. In sliding query, readings of WSN IDS are masterminded where metrics with the most amazing weight are at best. Fitting IDS apparatus might be chosen in the wake of coordinating the measurements weight and WSN IDS highlights.

\section{REMOTE SENSOR NETWORK AND INTRUSION DETECTION SYSTEM}

WSN are self-masterminded and base less removed gadgets, for example, heat, clamor, dampness, and so forth., to screen the world or physical conditions. WSN moves their information accumulated through the plan to a central locale called base station with the goal of separating the information for further arrangement. WSN is sent in the circumstances that are commonly hostile and hazardous. WSN has incalculable from which achieves new troubles. The sensor center points have faulty medium correspondence and absurd limits of advantages that render the transmission of security framework exceedingly troublesome. Figure 1 demonstrates the middle WSN system. An enormous bit of the shows for WSNs in the past acknowledged that all center points are trustworthy and accommodating. Regardless, this isn't the circumstance for a few, sensor orchestrate applications today and a combination of strikes are possible in WSN. Discovery of interruption is the way to distinguish unwanted operation on a machine or gadget. IDS may be programming or machinery that arranges motion with a particular end objective to differentiate unwanted intervention from displays. A WSN IDS is one that can investigate WSN particular movement; it likewise incorporates examining for outside clients attempting to associate with the system through access focuses (AP). 
IDS assume imperative part in securing as systems progressively bolster WSN advancements at different purposes of a topology. An IDS usage framework is that the information ought to be transmitted any place a WAP is proposed to pursue a lot of endeavored assaults. It is possible to join together or decentralize WSN IDS. In bound together IDS coordinate sensors collect and pass rehash information to a concentrated association support, where the WSN IDS information are verified and dealt with for perceiving impedance. Then another time, a decentralized WSN IDS for the most part execute rehearses which are finished by both the sensors and the assistance. Decentralized is perfect for more diminutive evaluated WSN, and it is also dynamically taught. At the point when WSNs are bigger, an engaged WSN IDS is utilized to deal with information less testing and possible. WSN IDS sections integrate sensors, databases, servers, and consoles for administration registration. It is possible to operate WSN IDSs together or decentralized. In unified frameworks, the information are connected at a focal area with the goal that the choices and activities are made in view of that information. The sensor programming can be used to perceive strikes inside the extent of the IDS. The product utilized as a part of sensors may likewise implement security approaches on the sensor hubs, Giving restricted access to WSN interfaces, for instance. A connected scheme connects different components of WSN IDS to each other. Standard schemes or distinct administration scheme of the association can be used for interchanges in the section of WSN IDS. To control the partition between the WSN and wired systems, an administration arrangement or a standard system can be used. WSN IDS is another innovation, so there are a couple of downsides worried about it. Before implementing WSN IDS to a present detector arrangement, some caution should be mulled over. Because it is another development, it may contain bugs and provisions of escape. WSN IDS innovation, which can weaken the sensor system's safety standard or even increase its vulnerabilities from a pessimistic point of view. Another disadvantage with the WSN IDS is its cost that might be excessively costly, making it impossible to bear, especially when we have a huge scope of sensor systems, which may require extra sensors to deal with the whole system scope. WSN IDS execution relies on how it is organized by the structure manager. In the event that they are tuned beneficially or are pre - arranged to discover what precisely ought to on the sensor sort out, by then their capacity to their ideal limit. Regardless, obviously, a WSN IDS can be very insufficient. It would show more perplexity for the director to generate several false positives or false negatives. When all is said in done, IDSs are extremely inclined to false alerts, in this manner, keeps tuning is required for viable interruption recognition. WSN IDS adequacy relies upon chairmen who react in the wake of dissecting WSN information assembled

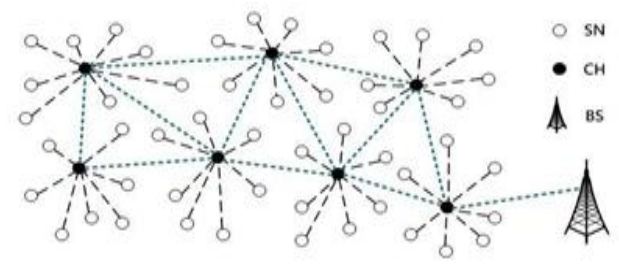

by IDS. A WSN IDS may involve a more fundamental amount of points of concern than wired IDS because it requires to tackle both the prepared information and the vow to compose the aggressors by the WSN IDS. WSN's headway runs hand in hand with vulnerabilities that wired frameworks do not regularly cope with, for example, promoting each structure sensor. WSN IDS must give the properties, for instance, If the sensor arrange safety is needed, confidentiality, authenticity, integrity, and availability. Regardless of these different downsides with WSN IDS, when used adequately and choreographed genuinely, it can offer a striking safety response to a sensor draw.

\section{WSN IDS METRICS}

An assortment of WSN IDS ideas are accessible in the writing having diverse highlights and capacities. The choice procedure for choosing an IDS can be isolated into the accompanying advances:

1). Distinguish the requirement for IDS by performing hazard evaluation of the association.

2). Understanding specialized condition of associations WSN.

3). Perform money saving advantage investigation.

4). Apply client prerequisites weight based way to deal with pick and actualize right IDS.

5). Perform vital organization of IDS.

6). Observing and support of IDS.

\section{WSN IDS METRICS}

Here of paper, we will discuss in progressively conspicuous detail the estimations that are most suitable to WSN IDS. The estimations are amassed by classes that are trailed by an administrator metric, including occurrences of low, common, and high scores. For curtness' inspiration, we wo stay away from cases for every estimation. The WSN IDS will be scattered into Logistical (class 1), Architectural (class 2), and Performance (class 3 ) one as appeared in figure 2 and is portrayed underneath in detail.

A.Logistical Metrics (Class 1): Logistical estimations are utilized to assess cost, common sense, and sensibility of a WSN IDS. The estimations depict essential to WSN IDS here are appeared in Table 1.

Other decided estimations that can be intertwined are: Documentation quality, Available duplicate assessment, Quality of explicit help, and so on.

A minimum necessity example of the decided estimations for WSN IDS is Distributed Management:

Low Score: Management of every sensor must be done at the sensor itself.

High Score: Complete association of all sensors might be done from any sensor or remotely. Fitting encryption and endorsement instrument might be utilized. Measures such as configuration problems, policy help, license management and so on are suitable given that products with poor results in these regions would not be anything but hard to use in a distributed scenario with countless detectors. Stage necessities offer a hint of the framework resources in the asset fundamental WSN situation that will be devoured by the WSN IDS. 
B. Structural Metrics (Class 2): Engineering estimations are in a general sense used to look at the typical increase and working of the WSN IDS and how they sort out the sending plan. These estimations study the assistant benefit of the IDS. The estimations depicted here are appeared in Table 2.

An illustrative situation of other architectural estimates that may be included are: Anomaly-based, Misuse-based, Autonomous Learning, Host / OS Security, Interoperability, Package Content, Process Security, Signature-based, and Visibility, etc.

C.Performance Metrics (Class 3): Performance estimates are used to assess a WSN IDS restriction to perform a specific effort and fit within the objectives for execution. These estimates measure and assess the parameters affecting the execution of the WSN IDS. Table 3 shows the estimates delineated around it.

execution results for WSN IDS is False Positive Ratio watched: - Low Score: WSN IDS produces raised False Positive Ratio watched - Average Score: WSN IDS produces standard False Positive Ratio viewed $•$ High Score: WSN IDS makes practically zero False Positive Ratio viewed.

\section{MAPPING USER DESIRES TO METRIC(S)}

The estimations related with all of conceivable client basic are given in table 4 . The table displays what estimations are adding to satisfy a specific need. For instance size of client WSN is worry with the estimations Distributed Management, Platform needs, adaptable Sensitivity, Load

Changing Scalability and Multiple Sensor Support as appeared in the piece diverging from basic number 1 . The motivation driving the table is to help client in picking a right decision to IDS. Figure 3 gives client necessity to IDS metric weighting. Following documentations are utilized to speak to weighted client prerequisites and weighted WIDS measurements relationship illustration. As in a difficult situation gets most essential weight, so the IDS thing having scarcest inconvenience in planning has every one of the reserves of being the best response for the customer condition for this situation. It is moreover possible that a bit of the estimations discussed above may not add to any of the customer essential. As WSN development is changing more estimations and request may be added to the above methodology.

\section{CONCLUSION}

An assortment of IDS ideas are proposed for remote sensor systemsHowever it is hard for the customer to pick one of them that fulfills their needs as these thoughts change in highlights and limits. In this record, we outfit a client with weight-based preconditions for overseeing how to pick an IDS thought so it very well may be refreshed to give sensor association security. We portray various advances required for the selection of IDS and how customer essentials may be weighted. We likewise characterize different measurements worry with remote sensor arrange IDS and how mapping of weighted client necessities to these measurements should be possibleAlthough we have attempted our most extreme to investigate the client needs and measurements worried about IDS, a critical advance should be taken to discover more. The

methodology inspected in the paper may be connected by allocating negative and division loads to the customer essentials with the objective that increasingly definite assurance of IDS should be conceivable.

\section{REFERENCES}

[1] Kumarave A., Rangarajan K.,Algorithm for automaton specification for exploring dynamic labyrinths,Indian Journal of Science and Technology,V-6,I-SUPPL5,PP-4554-4559,Y-2013

[2] P. Kavitha, S. Prabakaran "A Novel Hybrid Segmentation Method with Particle Swarm Optimization and Fuzzy C-Mean Based On Partitioning the Image for Detecting Lung Cancer" International Journal of Engineering and Advanced Technology (IJEAT) ISSN 2249-8958, Volume-8 Issue-5, June 2019

[3] Kumaravel A., Meetei O.N.,An application of non-uniform cellular automata for efficient cryptography,2013 IEEE Conference on Information and Communication Technologies, ICT 2013,V-,I-,PP-1200-1205,Y-2013

[4] Kumarave A., Rangarajan K.,Routing alogrithm over semi-regular tessellations,2013 IEEE Conference on Information and Communication Technologies, ICT 2013,V-,I-,PP-1180-1184,Y-2013

[5] P. Kavitha, S. Prabakaran "Designing a Feature Vector for Statistical Texture Analysis of Brain Tumor" International Journal of Engineering and Advanced Technology (IJEAT) ISSN: 2249-8958, Volume-8 Issue-5, June 2019

[6] Dutta P., Kumaravel A.,A novel approach to trust based identification of leaders in social networks,Indian Journal of Science and Technology,V-9,I-10,PP--,Y-2016

[7] Kumaravel A., Dutta P.,Application of Pca for context selection for collaborative filtering,Middle - East Journal of Scientific Research,V-20,I-1,PP-88-93,Y-2014

[8] Kumaravel A., Rangarajan K.,Constructing an automaton for exploring dynamic labyrinths,2012 International Conference on Radar, Communication and Computing, ICRCC 2012,V-,I-,PP-161-165,Y-2012

[9] P. Kavitha, S. Prabakaran "Adaptive Bilateral Filter for Multi-Resolution in Brain Tumor Recognition" International Journal of Innovative Technology and Exploring Engineering (IJITEE) ISSN: 2278-3075, Volume-8 Issue-8 June, 2019

[10] Kumaravel A.,Comparison of two multi-classification approaches for detecting network attacks, World Applied Sciences Journal,V-27,I-11,PP-1461-1465,Y-2013

[11] Tariq J., Kumaravel A.,Construction of cellular automata over hexagonal and triangular tessellations for path planning of multi-robots,2016 IEEE International Conference on Computational Intelligence and Computing Research, ICCIC 2016,V-,I-,PP--,Y-2017

[12] Sudha M., Kumaravel A.,Analysis and measurement of wave guides using poisson method,Indonesian Journal of Electrical Engineering and Computer Science, V-8,I-2,PP-546-548,Y-2017

[13] Ayyappan G., Nalini C., Kumaravel A., Various approaches of knowledge transfer in academic social network,International Journal of Engineering and Technology,V-,I-,PP-2791-2794,Y-2017

[14] Kaliyamurthie, K.P., Sivaraman, K., Ramesh, S. Imposing patient data privacy in wireless medical sensor networks through homomorphic cryptosystems 2016, Journal of Chemical and Pharmaceutical Sciences 92.

[15] Kaliyamurthie, K.P., Balasubramanian, P.C.An approach to multi secure to historical malformed documents using integer ripple transfiguration 2016 Journal of Chemical and Pharmaceutical Sciences 92.

[16] A.Sangeetha,C.Nalini,"Semantic Ranking based on keywords extractions in the web", International Journal of Engineering \& Technology, 7 (2.6) (2018) 290-292

[17] S.V.GayathiriDevi,C.Nalini,N.Kumar,"An efficient software verification using multi-layered software verification tool "International Journal of Engineering \& Technology, 7(2.21)2018 454-457

[18] C.Nalini,ShwtambariKharabe,"A Comparative Study On Different Techniques Used For Finger - Vein Authentication", Internationa Journal Of Pure And Applied Mathematics, Volume 116 No. 82017 , 327-333, Issn: 1314-3395 
[19] M.S. Vivekanandan and Dr. C. Rajabhushanam, "Enabling Privacy Protection and Content Assurance in Geo-Social Networks", International Journal of Innovative Research in Management, Engineering and Technology, Vol 3, Issue 4, pp. 49-55, April 2018.

[20] Dr. C. Rajabhushanam, V. Karthik, and G. Vivek, "Elasticity in Cloud Computing", International Journal of Innovative Research in Management, Engineering and Technology, Vol 3, Issue 4, pp. 104-111, April 2018.

[21] K. Rangaswamy and Dr. C. Rajabhushanamc, "CCN-Based Congestion Control Mechanism In Dynamic Networks", International Journal of Innovative Research in Management, Engineering and Technology, Vol 3, Issue 4, pp. 117-119, April 2018.

[22] Kavitha, R., Nedunchelian, R., "Domain-specific Search engine optimization using healthcare ontology and a neural network backpropagation approach", 2017, Research Journal of Biotechnology, Special Issue 2:157-166

[23] Kavitha, G., Kavitha, R., "An analysis to improve throughput of high-power hubs in mobile ad hoc network" , 2016, Journal of Chemical and Pharmaceutical Sciences, Vol-9, Issue-2: 361-363

[24] Kavitha, G., Kavitha, R., "Dipping interference to supplement throughput in MANET" , 2016, Journal of Chemical and Pharmaceutical Sciences, Vol-9, Issue-2: 357-360

[25] Michael, G., Chandrasekar, A.,'Leader election based malicious detection and response system in MANET using mechanism design approach", Journal of Chemical and Pharmaceutical Sciences(JCPS) Volume 9 Issue 2, April - June 2016

[26] Michael, G., Chandrasekar, A.,"Modeling of detection of camouflaging worm using epidemic dynamic model and power spectral density", Journal of Chemical and Pharmaceutical Sciences(JCPS) Volume 9 Issue 2, April - June 2016.

[27] Pothumani, S., Sriram, M., Sridhar, J., Arul Selvan, G., Secure mobile agents communication on intranet,Journal of Chemical and Pharmaceutical Sciences, volume 9, Issue 3, Pg No S32-S35, 2016

[28] Pothumani, S., Sriram, M., Sridhar, Various schemes for database encryption-a survey, Journal of Chemical and Pharmaceutical Sciences, volume 9, Issue 3, Pg NoS103-S106, 2016

[29] Pothumani, S., Sriram, M., Sridhar, A novel economic framework for cloud and grid computing, Journal of Chemical and Pharmaceutical Sciences, volume 9, Issue 3, Pg No S29-S31, 2016

[30] Priya, N., Sridhar, J., Sriram, M. "Ecommerce Transaction Security Challenges and Prevention Methods- New Approach" 2016 ,Journal of Chemical and Pharmaceutical Sciences, JCPS Volume 9 Issue 3.page no:S66-S68

[31] Priya, N.,Sridhar,J.,Sriram, M."Vehicular cloud computing security issues and solutions" Journal of Chemical and Pharmaceutical Sciences(JCPS) Volume 9 Issue 2, April - June 2016

[32] Priya, N., Sridhar, J., Sriram, M. "Mobile large data storage security in cloud computing environment-a new approach" JCPS Volume 9 Issue 2. April - June 2016

[33] Anuradha.C, Khanna.V, "Improving network performance and security in WSN using decentralized hypothesis testing "Journal of Chemical and Pharmaceutical Sciences(JCPS) Volume 9 Issue 2, April - June 2016

[34] Anuradha.C, Khanna.V, "A novel gsm based control for e-devices" Journal of Chemical and Pharmaceutical Sciences(JCPS) Volume 9 Issue 2, April - June 2016.

[35] Anuradha.C, Khanna.V, "Secured privacy preserving sharing and data integration in mobile web environments "Journal of Chemical and Pharmaceutical Sciences(JCPS) Volume 9 Issue 2, April - June 2016.

[36] Sundarraj, B., Kaliyamurthie, K.P. Social network analysis for decisive the ultimate classification from the ensemble to boost accuracy rates 2016 International Journal of Pharmacy and Technology 8

[37] Sundarraj, B., Kaliyamurthie, K.P. A content-based spam filtering approach victimisation artificial neural networks 2016 International Journal of Pharmacy and Technology 83 .

[38] Sundarraj, B., Kaliyamurthie, K.P. Remote sensing imaging for satellite image segmentation 2016 International Journal of Pharmacy and Technology 83.

[39] Sivaraman, K., Senthil, M. Intuitive driver proxy control using artificial intelligence 2016 International Journal of Pharmacy and Technology 84.

[40] Sivaraman, K., Kaliyamurthie, K.P. Cloud computing in mobile technology 2016 Journal of Chemical and Pharmaceutical Sciences 92.
[41] Sivaraman, K., Khanna, V. Implementation of an extension for browser to detect vulnerable elements on web pages and avoid click jacking 2016 Journal of Chemical and Pharmaceutical Sciences 92.

\section{AUTHORS PROFILE}

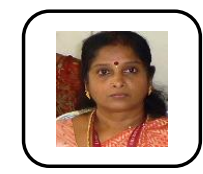

C.Nalini, Associate Professor, Department of Computer Science \& Engineering, Bharath Institute of Higher Education and Research, Chennai, India

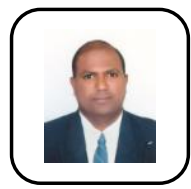

C. Rajabhushanam, Associate Professor, Department of Computer Science \& Engineering, Bharath Institute of Higher Education and Research, Chennai, India

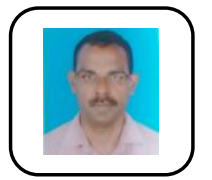

Stephen Anto Jegan, Assistant Professor, Department of Computer Science \& Engineering, Bharath Institute of Higher Education and Research, Chennai, India 